\title{
Sinkretisme as missiologiese uitdaging
}

J J Kritzinger en S J J Niemand ${ }^{1}$

(Universiteit van Pretoria)

\section{ABSTRACT}

\section{Syncretism as missiological challenge}

Religious syncretism is usually seen as the intermingling of two religious systems to the extent that the uniqueness of a specific religion is compromised. It is thus understood as missiologically negative. This article attemps to view this from another - and more positive - angle. Here we show how the process of inculturation, the "incarnation" of the gospel within a culture is not much different from the process we term "positive syncretism". It is also possible that the process could veer off in a negative direction. This process therefore remains a formidable challenge to mission in the sense that while there are always new cultural worlds to be penetrated by the gospel, the process cannot be controlled by any "outsiders". This theory is applied and tested by looking at the phenomenon of African Independent Churches, and a simple two-dimensional model is developed as illustration of a typology.

\section{INLEIDING}

Dit het reeds konvensie geword om sinkretisme slegs in 'n negatiewe lig te sien, anders as terme soos kontekstualisasie en inkulturasie ${ }^{2}$ wat as 'n positiewe doelwit vir sending beskou word. In hierdie artikel, wat hoofsaaklik gebaseer is op navorsing betreffende die Onafhanklike Swart Kerke wil ons egter meer genuanseerd omgaan met sinkretisme,

1 Dr S J J Niemand het sy PhD graad in 2000 aan die Universiteit van Pretoria verwerf. Prof J J Kritzinger was sy promotor. Hierdie artikel maak in besonder gebruik van hoofstuk 7 van eg se proefskrif.

2 Ons sal hier net oorsigtelik ingaan op die verskillende gebruike van die terme kontekstualisasie en inkulturasie, en hulle verskille en ooreenkomste. Hieroor is al baie gehandel. Ons kan hier slegs verwys na Bosch (1991:420-457) se behandeling. In wat volg gebruik ons meestal inkulturasie, en wel op ' $n$ wyse wat taamlik parallelle vertoon met wat ons noem positiewe sinkretisme. By kontekstualisasie, hoewel dit baie dieselfde drakrag het, word ietwat meer klem gelê op die sosio-politieke konteks as die kulturele. In hierdie artikel fokus ons meer op die kulturele dimensie, in die mate wat hierdie onderskeid gehandhaaf kan word. 
en onder andere onderskei tussen positiewe en negatiewe sinkretisme ${ }^{3}$. Sinkretisme bied ' $n$ tweërlei missiologiese uitdaging: om die negatiewe sinkretisme (ongeoorloofde godsdienstige vermenging) te vermy, en om die positiewe sinkretisme (oftewel inkulturasie) te bevorder.

\section{KULTUUR}

Kultuur is die unieke en omvattende plan vir die lewe van ' $\mathrm{n}$ groep mense, ' $n$ plan waarin hulle lewens- en wêreldbeskouing tot uitdrukking $\mathrm{kom}^{4}$. Dit is húlle unieke plan en omvat alle aspekte van hulle lewe. Elke kultuur het as sodanig dan ook 'n eie persoonlikheid of individualiteit. Niemand moet hierdie kultuur van buite volgens die maatstaf van sy eie kultuur beoordeel nie.

Elke kultuur het ook ' $n$ saambindende krag. Meestal word religie as hierdie saambindende krag beskou ${ }^{5}$. Dit deursuur alle fasette van ' $\mathrm{n}$ kultuur, die mens-, lewens- en wêreldbeskouing, denkpatrone, kultiese gebruike en rituele, volksgewoontes en ekonomie.

Dit hoef dus amper nie gesê te word nie dat in die kommunikasie van die evangelie daar ' $\mathrm{n}$ fundamentele konfrontasie met die kulturele sisteem plaasvind (of behoort plaas te vind), omdat die christelike geloof in konflik kom met die "hart" van enige kultuur.

\section{EVANGELIE EN KULTUUR}

Daar moet onderskei word tussen evangelie en kultuur. As ons dit nie doen nie word ons eie kultuur die evangelie, en verwar ons kulturele relatiwismes en Bybelse absolutes (Hiebert 1976:58). Bosch (1991:

3 J Beyers (2003) het in ' $n$ artikel uitvoerig ingegaan op die verskillende aspekte van sinkretisme. Ons onderskeid tussen positiewe en negatiewe sinkretisme is maar één van die moontlike onderskeidings. Ons gebruik dié onderskeiding hier om die beredenering eenvoudig te hou, want ons belangstelling in hierdie artikel is prakties-missiologies.

4 Daar is baie definisies van kultuur, hoewel daar redelike eenstemmigheid is daaroor dat dit omvattend verstaan behoort te word. Ons formulering hierbo is nie ver van dié van Hiebert (1976:45) nie, wat sê: "Culture is the integrated system of learned behaviour, ideas and products characteristic of a society".

5 Soms word kultuur voorgestel as 'n aantal konsentriese sirkels met die buitenste vlak die sigbare "produkte", dan die gewoontes, die waardes, en die lewens- en wêreldbeskouing, met as sentrum die religieuse ondergrond. So gesien is religie dan ' $n$ deel van, en wel ' $n$ beslissende deel van, kultuur. In hierdie opsig moet "religie" dan onderskei word van "geloof" (ten minste in die christelike sin van die woord). 
$291 \mathrm{vv}$ ) dui baie duidelik aan hoedat die "verligte" Westerlinge van die 19de eeu dit baie moeilik gevind het om nie hulle eie "hoëre" kultuur ("beskawing") in "n pakket saam met die evangelie aan te bied nie.

Ben Marais (1964:169-170) behandel die 5 klassieke benaderings teenoor kultuur.

1 Tertullianus, Kierkegaard en ander se houding kan genoem word: Christus is vyand van die kultuur.

2 Abelardus verteenwoordig dié wat voel: Christus is van die kultuur.

3 Thomas van Aquinas sou sê: Christus is bo die kultuur.

4 Luther: Christus en die kultuur staan paradoksaal teenoor mekaar.

5 Hierteenoor is Augustinus, Calvyn, Wesley en ander se standpunt: Christus is die Verlosser van die kultuur ${ }^{6}$.

In die praktyk, sê hy, het die deursnee sendeling teenoor sy eie natuur Abelardus se standpunt gevolg, maar teenoor die Afrika-kultuur dié van Tertullianus!

' $n$ Mens is maar té geneig om jou eie kultuur as die maatstaf te neem.

\section{SINKRETISME AS GEVAAR}

"Overal waar het evangelie komt", sê Van den Berg (1966:15), "stuit het op pogingen die het willen inkapselen in de bestaande godsdiensten en levenspatronen... Het probeert altijd het evangelie om te buigen en ondergeschikt te maken aan heersende religies en filosofische stelsels". Dít is die essensie van wat bekend geword het as christelike "sinkretisme"... dat in die ontmoeting van die christendom met ander godsdienstige sisteme die essensies van die christelike geloof ondergrawe word deur elemente van die ander religie.

Van den Berg meen dat daar in Afrika vier groepe onderskei kan word ten opsigte van hulle reaksie op die evangelie (1966:32-36). Sinkretisme sal telkens anders vertoon. Die eerste groep is nog onaangeraak deur die evangelie. Daar is dus geen sprake van sinkretisme nie. Feitlik dieselfde kan van die tweede groep gesê word:

6 Bavinck (1949:77) sê byvoorbeeld: “...Jesus Christ is not the great destroyer of all the products of human culture, but the great renewer and re-generator". 
hulle het die evangelie bewustelik verwerp. Hoogstens sal hulle gebruikmaak van die vrugte van die sending in die vorm van (Westerse) onderwys, mediese dienste, en so meer, maar hulle wou nie christene word nie ${ }^{7}$. Die derde groep, weer, het die evangelie grondig aangeneem, en die Heilige Gees het 'n vormende invloed in hulle lewe geword. Hier en daar sal sinkretisme (in negatiewe sin) dreig, maar namate daar groei in die geloof en kennis is, word sinkretisme al minder van ' $\mathrm{n}$ gevaar.

Dit is die vierde groep wat eintlik ter sake is. Hulle het die evangelie aanvaar, maar soveel van hulle ou gedagtewêreld daar ingedra dat die evangelie van binne uit kragteloos gemaak word deur die vermenging. Hierdie sinkretisme is in die praktyk grootliks ' $n$ spontane proses" ${ }^{8}$, maar daar is ook groeiende pogings tot ' $\mathrm{n}$ doelbewuste sinkretisme ${ }^{9}$.

\section{POSITIEWE SINKRETISME: INHEEMSWORDING EN INKULTURASIE}

Enige sendeling wat die naam werd is, het wel spoedig besef dat sy oorgeërfde kerklike tradisies - en die oordrag van die evangelie aangepas moet word aan die kultuur van die ontvangers. Dié moeisame proses is "inheemswording" genoem... die klem was op " $n$ inheemse kerk, waar mense kan tuis voel. Gaandeweg - wanneer die sendelinge tevrede was dat die mense die evangelie (soos húlle dit verstaan) genoegsaam hulle eie gemaak het - sou die kerk "onafhanklikheid" verwerf, ' $n$ onafhanklike inheemse kerk sou tot stand kom.

7 Onder die Xhosa was daar algemeen twee groepe onderskei: die "rooi mense" (tradisionaliste) en "skool mense" (die christene).

8 So Van den Berg (1966:33-34), maar ook Kraemer (1938:209). Aan die een kant verloop hierdie spontane proses passief, sê Van den Berg. Dit is wanneer die kennismaking met die evangelie so oppervlakkig geskied het dat daar geen werklike konfrontasie plaasgevind het nie. Die evangelie is nie verwerp nie, dit is aanvaar, maar dit het nie deel geword van die persoon nie... iets soos 'n glasoog, sê Van den Berg (1966:35): "Het bevindt zich in de oogholte. Het kan zelfs bedriegelijk veel op een echt oog lijken. Maar het heeft geen organische verbinding met het lichaam. Het functioneert niet. Het is geen licht binnen. Het lichaam blijft donker".

9 Hierdie beweging is natuurlik nie net beperk tot die christelike geloof en tot Afrika nie. Dit is bv die Bahai' godsdiens se uitdruklike bedoeling. In die postmoderne era word orals pogings aangewend om die absolute aansprake van godsdienste af te water en die gemeenskaplikhede te beklemtoon. 
Kenmerkend van hierdie fase was die feit dat die besluite oor wat "aanvaarbaar inheems" was by die sendelinge gelê het: húlle sou besluit wanneer die doelwit bereik is.

Gedurende die afgelope paar dekades het missioloë egter toenemend bewus geword van die noodsaaklikheid dat die evangelie op ' $n$ meer ingrypende wyse in die kulture geïnkarneer moet word. Die evangelie moet ingroei in die kulturele konteks... dit moet tuiskom. ' $n$ Nuwe term is geskep: inkulturasie. Dit het ' $n$ baie belangrike saak geword. Die moderne sendingbeweging het histories uitgegaan van ' $n$ euro-Christendom, wat dikwels as gevolg van ' $n$ kulturele arrogansie grootliks onnadenkend hulle kultuur op die ontvangers (Afrikane) afgedruk het. Die ontvangers kon nie onderskei tussen die essensie van die evangelie en die kultuur van die sendelinge nie. Die hele pakket is dus aanvaar... of verwerp. Dikwels was die evangelie wat gevestig geraak het, egter vir die Afrikaan vreemd, iets wat talle van hulle (aanvanklik) as onvermydelik aanvaar het. Sedert die 1960s het die ontvangers van die evangelie egter toenemend daarop aangedring dat die proses van kontekstualisasie (in ' $n$ wyer sin) en inkulturasie (in ' $n$ enger sin) in hulle eie hande moes wees.

In " $n$ sekere sin het die "sendelinge" dus in die proses van inkulturasie belangstellende toeskouers geword... die inisiatief het uit hulle hande oorgegaan na die christene wat vroeër net die ontvangers van die evangelie was. Die proses om die evangelie betekenisvol gestalte te laat vind binne ' $n$ bepaalde kultuur het nou op ' $n$ nuwe vlak aangekom.

\section{SUKSESVOLLE INKULTURASIE AS ANTWOORD}

Om inkulturasie betekenisvol te laat plaasvind, sal (inheemse) Christenleiers en gemeenskappe toegelaat moet word om self besluite vir en in verband met die verloop daarvan te neem. As kulturele en religieuse gemeenskap moet hulle insien dat hulle as volk van God, liggaam van Christus en tempel van die Heilige Gees die primêre plek is waar inkulturasie tot sy volle reg moet kom. Vir gesonde inkulturasie is dit egter krities dat die katolisiteit van die kerk tot sy reg sal kom. Plaaslike gelowiges sal ook die inset van kundige gelowiges van buite moet benut. Dikwels is dit nie die geval nie, en verval ' $n$ groep in ' $n$ 'independentisme' met gepaardgaande negatiewe sinkretisme.

Die rol van buitestanders in die proses is van kritiese belang, maar ook baie delikaat. Beide ' $n$ totale verwerping as ' $n$ onkritiese aanvaarding van die kulturele konteks open die deure vir negatiewe 
sinkretisme. Om te verhoed dat dit gebeur, sal daar krities op die konteks waarin die evangelieboodskap beslag moet vind, gelet moet word. Dit kan genoem word "kritiese kontekstualisasie" (Hiebert 1999).

Kritiese kontekstualisasie sal met die volgende voorwaardes gepaard moet gaan.

* Die plaaslike gemeenskap moet die behoefte insien en aanvaar dat hulle kultuur en godsdiens in die lig van die Bybel onder die soeklig geplaas moet word.

* Hulle moet gelei word om ' $n$ kritiese voorraadopname van al die waardesisteme en strukture waaruit hul kultuur bestaan, te doen.

* Hulle moet langs die weg van Skrifstudie in die begrip van die Bybelse boodskap begelei word. Hierdie is ' $n$ baie belangrike fase, want indien die plaaslike Christelike gemeenskap nie die Bybelse norme en waardes erken nie, sal hulle nie in staat wees om hul eie situasie krities te evalueer nie.

* Die gemeenskap moet begelei word om vanuit die Skrif hulle verlede en kultuur krities in oënskou te neem. Hiebert (1999:187) maak hier die volgende belangrike opmerking: "It is important here that the people themselves make the decision, for they must be sure of the outcome before they will change". Die gemeenskap sou hier op verskillende wyses kon reageer. Aan die een kant sou hulle baie van die ou gebruike kon behou, solank dit nie in stryd met die Skrif is nie; ander gebruike sal hulle weer verwerp, omdat dit gedragspatrone is wat nie by " $n$ Christelike lewenswyse pas nie. Nog ander gebruike sou weer omvorm kon word om nuwe, Christelike inhoude daaraan te gee.

* Die gemeenskap moet vervolgens begelei word om die nuwe gebruike in rituele vas te lê, en sodoende uitdrukking gee aan ' $n$ Christelike lewenswyse.

Suksesvolle of betekenisvolle inkulturasie sal dus poog om onder alle omstandighede getrou te wees aan beide die Skrif en die inheemse kultuur. Die doel van ' $n$ gesonde proses van inkulturasie is dat mense hulle solidariteit kan beleef beide binne die gegewe van hulle eie kultuur en ook binne die koninkryk van God.

Schineller (1992:53) beskou die volgende grondhoudings hiervoor as belangrik: 
* Betekenisvolle inkulturasie vra waagmoed, en ' $n$ absolute vertroue op die aktiewe, alomteenwoordige leiding van die Heilige Gees.

* Sonder vryheid kan daar geen kreatiwiteit wees nie. Natuurlik het vryheid sy perke, maar daar moet verdraagsaamheid teenoor verskeidenheid en verandering wees. Aanpassing moet positief aangemoedig word. Binne die raamwerk van die Skrif moet daar vryheid wees om die evangelie te inkultureer.

* Daar moet verby die grense van die plaaslike kerk gefokus word op die koninkryk en heerskappy van God. Die kerk moet getuig van en in diens van hierdie koninkryk staan, anders raak die fokus verskraal.

* Verandering geskied nie oornag nie, en kan soms ' $\mathrm{n}$ pynlike proses wees. Daar moenie oorhaastig te werk gegaan word nie. Geduld met mense wat die sake anders verstaan en beleef, is van die grootste belang.

* Die Skrif help ons om te verstaan hoe God werksaam is in die lewens van mense en kulture. Met die Skrif as die bril waardeur ons kyk sien ons die liefde van God vir alle mense binne alle kulture raak.

* Aanvoeling en respek vir God se kinders is nodig. Die doelwit moet wees om dit vir die gelowiges moontlik te maak om hulle getuienis met integriteit uit te leef.

* Suksesvolle inkulturasie vra dat aandagtig geluister en steeds onbevange geluister word... na beide die evangelieboodskap én na kulture in al hulle verskeidenheid.

* Vooroordele en alle vorms van paternalisme moet afgelê word. Daarsonder sal daar geen rol gespeel kan word in betekenisvolle kritiese inkulturasie nie.

Die proses van inkulturasie is delikaat en moeilik, en stel baie eise, maar dit bied ' $n$ opwindende uitdaging (Schineller 1992). Die uitdaging wat dit bied, is volgens Whiteman (1997:6): "How do we carry out the Great Commission and live out the Great Command in a world of cultural diversity with a Gospel that is both truly Christian in content and culturally significant in form"?

Betekenisvolle inkulturasie stel dus die volgende uitdagings aan die missiologie:

* Dit het met die verandering of transformasie van die konteks te doen - in hierdie sin bied dit dus 'n profetiese uitdaging. 
* Dit verbreed die begrip van die evangelie omdat daar vanuit ' $\mathrm{n}$ ander kulturele perspektief op die Skrif gefokus word. Inkulturasie bring dus ' $n$ hermeneutiese uitdaging mee.

* Die draers van die evangelieboodskap word self deur die proses verander, want hulle word nou deel van ' $\mathrm{n}$ liggaam wat anders is as waaraan hulle gewoond is. Inkulturasie bied dus ' $\mathrm{n}$ persoonlike uitdaging.

Die vleesgeworde Christus dien steeds as die model.

Net soos Hy homself ontledig en onder mense kom woon het, en deel (solidêr) van hulle geword het, net so moet die draers van die boodskap van Jesus Christus gewillig wees om dieselfde te doen wanneer hulle ' $n$ bepaalde kultuur met die evangelie nader. Karecki (1993:152) maak in hierdie verband die volgende opmerking:

"The inculturation of the gospel is no longer the prerogative of professional missiologists. It is not simply a 'workshop topic' which is offered for discussion. It is not an 'optional extra' for those who want to manifest a sensitivity to other cultures. Inculturation is an imperative...".

\section{7 'N ANDER PERSPEKTIEF OP SINKRETISME}

Religieuse sinkretisme word gewoonlik verstaan as die proses waardeur godsdienstige elemente van twee of meer godsdienstige kulture wat met mekaar in aanraking kom, saamgevoeg of vermeng word.

Aanvanklik, egter, het die term hoofsaaklik ' $n$ politieke kleur en positiewe betekenis gehad. Dit is gebruik om die versoening van elemente wat gewoonlik in botsing met mekaar verkeer, aan te dui. Algaande is hierdie begrip egter ook op ander sfere as net die politieke toegepas. Veral sedert die $17 \mathrm{de}$ eeu het dit ' $\mathrm{n}$ negatiewe konnotasie gekry, en is dit gebruik is om die ongeoorloofde versoening van twee teenstrydige teologiese en religieuse standpunte aan te dui. Van toe af het sinkretisme ' $n$ waarskuwende term geword wat gebruik is om die ware godsdiens teen dwaling of kettery te beskerm.

Wat ons egter hier bepleit, is dat daar weer gedeeltelik teruggekeer word na die oorspronklike betekenis van die begrip: daar moet ook gesoek word na die gesonde versoeningselement in sinkretisme. Indien die Christendom erns wil maak met die erkenning van kultuur, en die noodsaaklikheid van inkulturasie aanvaar word, 
soos hierbo aangedui, sal ' $\mathrm{n}$ ander dimensie van sinkretisme ook benadruk moet word, naamlik dat sinkretisme gesond kan wees. Sinkretisme bied nie net 'n negatiewe uitdaging aan die kommunikasie van die evangelie nie, maar dit daag die draer van die evangelie ook positief uit ${ }^{10}$.

Positief bied dit die uitdaging om skrifwaarhede self beter te begryp en in kultuurkonteks beter te interpreteer en te herinterpreteer. Dis 'n uitdaging om met die universele boodskap van 'n unieke en genadige God na kulture en godsdienste te gaan met waagmoed en geloof, maar sonder enige sweem van paternalisme of vooroordeel. Dis ' $\mathrm{n}$ uitdaging om daaraan mee te werk om die evangelie tot sy logiese konsekwensies betekenisvol in ' $n$ bepaalde kulturele en religieuse konteks te inkultureer.

Hoe kan die negatiewe sinkretisme in die multi-religieuse en multi-kulturele wêreld van vandag teengewerk word? In hierdie verband kan op die volgende gelet word (vgl ook Van der Merwe 1990:421 en Van Rooy 1964:50v).

* Alles wat die sentraliteit van die lewe, dood en opstanding van Jesus Christus ontken, is ' $n$ ontkenning van die evangelie self. Wanneer kontekstualisasie tot ' $n$ miskenning of geringskatting van die kruis en die opstanding van Jesus Christus lei, kan daar nie sprake wees van 'n suksesvolle proses van aanpassing of versoening nie. Die erkenning van die hoogste gesag van die Bybel (en daarmee saam die ekumeniese belydenisskrifte van die kerk) is nodig om negatiewe sinkretisme teen te werk.

* Daar mag nie twyfel daaroor wees nie dat die evangelie in Afrika anders as byvoorbeeld in Europa gebring moet word. Daar moet met die lewens- en wêreldbeskouing van die mense van Afrika en die probleme wat hulle ervaar, rekening gehou word. Die boodskap en teologie moet telkens aangepas word aan die denkpatrone van die hoorder. Alleen op hierdie wyse sal mense betekenisvol met die evangelie gekonfronteer word, en negatiewe sinkretisme teengewerk word. Telkens moet die leefwêreld van die hoorder verstaan word, sodat die evangelie die suurdeeg sal wees wat die hele gemeenskap sal deursuur.

10 Dit behoort vir die leser reeds duidelik te wees dat ons "positiewe sinkretisme" as grootliks sinoniem met "inkulturasie" beskou. Dit is teoreties moontlik dat die ineenvloei van kulture en godsdienste suksesvol kan wees. 
* Die kerugma moet die ou godsdiens en heidense elemente met waagmoed uitdaag en vir die Christendom in besit neem ${ }^{11}$. Hier moet egter nie oorhaastig te werk gegaan word nie. 'n Goeie voorbeeld hiervan was die oorhaastige aanpassing by die Griekse kultuur en denkwêreld wat tot die ontstaan van dwalings soos die Docetisme, Marcionisme en Montanisme gelei het (Bosch 1974:21).

Weliswaar bestaan daar nie ' $n$ veilige resep waarvolgens die kerk kan besluit watter elemente uit die tradisionele godsdiens in besit geneem kan word en waar ' $n$ negatiewe houding van pas is nie. So ' $n$ besluit kan alleenlik geneem word na deeglike bestudering van elke afsonderlike geval en onder die leiding van die Heilige Gees. Die basiese en nie-onderhandelbare elemente in die christelike boodskap, wat die kern daarvan vorm, mag nie prysgegee word nie.

Bavinck (1949:70) rapporteer oor ' $n$ Indiese konferensie wat die saak vir hulleself in 6 punte opgesom het:

1 Daardie gebruike wat essensieel is vir die christene, en vir die welwese van die kerk (bv monogamie) moet aanvaar word.

2 Daardie gebruike wat duidelik onchristelik is (soos afgodery, kaste, kleurvooroordele, ens) moet afgeskaf word.

3 Daardie gebruike wat sin maak, al vloei hulle voort uit die onchristelike sisteem (byvoorbeeld higiëne), kan aanvaar word.

4 Daardie gebruike wat sosiaal skadelik is (soos kinder-huwelike) moet gestaak word, of gewysig word.

5 Daardie gebruike wat nóg nie-christelik nóg skadelik is (soos kleredrag, aanbiddingswyses, ens), kan behou of afgeskaf word, soos ookal besluit mag word.

6 Daardie gebruike wat nóg onchristelik nóg skadelik is, maar hinderlik kan wees vir die verbreiding van die evangelie (soos bv ver-Indiese aanbiddingstyle wat vir Moslems onaanvaarbaar is) behoort ook laat vaar te word.

11 'n Baie interessante voorbeeld hiervan is die opdrag of raad wat Pous Gregorius (die Grote) in 601 aan Augustinus gegee het toe hy dié na die Angels (in die huidige Engeland) gestuur het: "The heathen temples of these people need not be destroyed, only the idols which are to be found in them... If the temples are well built, it is a good idea to detach them from the service of the devil, and adapt them for the worship of the true God..." (Neill 1964:59). 
Die basiese probleem is egter dat elemente van ' $n$ kultuur nie sommerso losgemaak kan word van die integrale lewens- en wêreldbeskouing wat dit onderlê nie. Tog, as daar fyn gekyk word na die nie-christelike kulture, lyk dit asof daar wel ' $n$ dualisme is: aan die een kant is daar die onontkenbare motief van self-vergoddeliking (die slang se "julle sal soos God wees" van Gen 3:4) strek dwarsdeur die menslike geskiedenis), maar aan die ander kant is daar ' $n$ motief wat steeds die stam red van verderf. Calvyn het opgemerk dat die heidene ' $n$ baie defektiewe insig het ten opsigte van die eerste tafel van die wet, maar tog ' $n$ merkwaardige insig vertoon ten opsigte van die beginsels van die tweede tafel. Hy skryf dit toe aan die oneindige goedheid van God wat ons nie aan onsself oorlaat nie (sien Bavinck 1949:76) ${ }^{12}$.

\section{IS DIE ONAFHANKLIKE AFRIKA KERKE ' $N$ VOORBEELD VAN POSITIEWE SINKRETISME?}

Terwyl ' $\mathrm{n}$ verskeidenheid faktore vir hulle ontstaan aangewys kan word, het hierdie kerke en bewegings hulle wortels in ' $n$ geestelike honger en diepgevoelde behoefte om self in hul eie konteks aan die Christendom waarmee hulle in aanraking gekom het uitdrukking te gee. Vandaar die teruggrype na die bewaring van die tradisionele kultuur- en godsdienseie. In hierdie proses het die inkulturasie soms te ver gegaan en het die kulturele of tradisionele dan verreweg die groter rol gespeel, terwyl skrifwaarhede verwater of buite rekening gelaat is. Die gevolg is dat negatiewe sinkretisme wyd voorkom ${ }^{13}$.

Die Christendom in Afrika is vandag ' $n$ aanvaarde feit, en vorm toenemend ' $n$ belangrike deel van die wêreld-Christendom. Daar moet egter ' $n$ begrip wees vir die spanningsveld waarin die AfrikaChristendom bestaan: aan die een kant is daar die eie religieuse tradisies en die tradisionele manier van leef en beleef, wat kenmerkend van die mense van Afrika is; en aan die ander kant is daar die veranderings-prosesse wat in Afrika afspeel. Afrika-Christene het soos die benaming aandui - hul reeds by Christus geskaar. Tog is daar klaarblyklik 'n groeiende behoefte om steeds aansluiting by die vitale

12 Bavinck pas dit toe ten opsigte van die konsep hao van die Sjinese filosofie (kinders se eerbied en ontsag teenoor ouers), een van die belangrikste grondslae vir ' $n$ gesonde samelewing. Dit is diep ingebed in die nie-christelike filosofie, maar ' $n$ waarde wat navolgenswaardig is. Ons sou dieselfde kon sê van ubuntu (die basiese gemeenskapsgevoel van die Afrikaan).

13 Niemand het in sy proefskrif hierdie verskynsel duidelik by die amaNazaretha aangetoon. Dit geld ook vir verskeie van die ander. 
kragte uit die tradisionele kultuur en godsdiens te soek, terwyl hulle ook vir die uitdagings van die moderne tyd oop wil wees. Dit bring dikwels mee dat Afrika-Christene moeite ondervind met opgelegde Euro-Christelike norme, belewingswyses en interpretasies wat die ontwikkeling van 'n eie Afrika-Christendom belemmer.

In die Suid-Afrikaanse konteks is hierdie spanningsveld duidelik waarneembaar. Hoe daar ook al geredeneer word, dit is ' $n$ feit dat die negatiewe invloede van die huwelik tussen die sending en kolonialisme en die on-Bybelse en onmenswaardige stelsel van apartheid en die gedwonge skeiding van mense diepgaande letsels in die lewe van swartmense meegebring het. Dit het hulle baie skepties gemaak oor die Euro-Christendom.

In die spanning wat deur die ontmoeting tussen die tradisionele Afrika en die moderne Weste teweeggebring is, bevind tradisionele Afrikane hulleself in 'n situasie van onsekerheid. Ook dít laat hulle teruggryp na die bekende in hul eie verlede: die religieuse en kulturele tradisies van Afrika. Hulle word gedwing om die moderne christelike (wat hulle aangeneem het) binne hul eie stel beginsels en waardes op te neem en toe te pas. In sommige gevalle bring dit mee die disintegrasie van die tradisionele holisme, en die ontstaan van 'n dualistiese wêreldbeeld. Dit kan die Christen-Afrikaan nog meer ontredderd laat.

Daar bestaan inderdaad die soeke na 'n dubbele kontinuïteit wat die plek en funksie van die tradisionele religieuse erfgoed in en vir die hedendaagse Afrikaan betref: 'n kontinuïteit met tradisionele religieuse praktyke as feit; en 'n kontinuïteit met getransformeerde tradisionele waardes as ideaal.

Veral sedert die 1960s is baie grondiger navorsing oor die tradisionele godsdiens in Afrika gedoen (vgl Verstraelen 1981:11). Wat uit hierdie studies na vore gekom het, is dat daar gesoek word, in die post-koloniale tydperk, na 'n nuwe identiteit. Hierdie identiteit moet christelik wees, maar ingeënt op die kulturele erfgoedere. Hiervan is die Onafhanklike Swart Kerke 'n sprekende voorbeeld.

Daar is soveel van die tradisionele waardes van Afrika wat waardeer moet word: die gemeenskapsgevoel (ubuntu), familie, gasvryheid, menslike verhoudinge, gesag, eerbied vir die tradisies en die gesag van ouers en leiers, ontsag vir die sakrale. Die tragiese is dat baie van hierdie positiewe waardes onder die impak van die Westerse waardes (ook die Christendom) daarmee heen is. Christene behoort die kulturele en religieuse erfenis van mense te respekteer, want daar moet 
rekening gehou word met die bemoeienis van God met alle mense. Aan die ander kant moet ook vasgehou word aan die algenoegsame skriftuurlike openbaring van God in verband met sy wil in en vir hierdie wêreld.

Die tradisionele erfgoed moet nie maar net verwerp word nie, maar daar moet daarmee rekening gehou word. Die geestelike kloof tussen "Christelik" en "Afrika", wat in die verlede so beklemtoon is, kan dalk hierdeur oorbrug word. Hierdie projek word "inkulturasie" genoem.

Daarom moet tradisionele rituele en gebruike met 'n nuwe Christelike inhoud gevul word. Die besef van die sakrale is byvoorbeeld sterk aanwesig, maar terselfdertyd baie tweeslagtig. Die teenwoordig-heid van taboes en vrees vir towery lei dikwels tot ' $n$ verlammende angs by mense. Hierdie vrees moet vanuit ' $n$ Christelike perspektief geban word deur die klem op 'n besef van God se liefdevolle uitnodiging tot vryheid.

Die Afrika-Christendom behoort egter nie slegs van 'n getransformeerde Afrika-verlede gebruik te maak nie, maar moet ook direk op die konkrete vrae en strewes van die moderne Afrikaan inspeel. Dit sal met situasies rekening moet hou waar baie mense oorgelewer is aan ellende, ongelykheid en uitbuiting, asook daardie situasies waar ontwikkeling van die een tot die onder-ontwikkeling van die ander gelei het, en steeds lei. Hierdie projek word veral "kontekstualisasie" genoem.

Hierdie is aspekte van die situasie waarvoor die Christelike kerk in Afrika te staan kom. Die konfrontasie van die evangelie met hierdie omstandighede kan geen enkele Christelike gemeenskap onverskillig laat nie.

\section{DIE ONAFHANKLIKE SWART KERKE DALK NIE DIE ANTWOORD NIE?}

Van die kant van ander Christene is verskillende benaderingswyses ten opsigte van hierdie kerke en bewegings moontlik. Een moontlikheid is eenvoudige verwerping en konfrontasie. Nog ' $n$ benadering is om hulle in minagting te ignoreer. " $n$ Derde benadering is om hulle aan te prys as die (enigste) antwoord op die uitdaging van inkulturasie/kontekstualisasie.

Soos reeds gesê, is daar baie wat ten opsigte van hierdie kerke en bewegings aangeprys en waardeer kan word. Die sterk samehorigheids- 
gevoel, die groot ruimte wat vir emosie, spontaneïteit, gevoel, sang en dans, wat so uniek aan die mense van Afrika is, gegee word, is van die aspekte wat te waardeer is. Die groei van hierdie bewegings is dan ook ' $n$ aanduiding dat hulle ' $n$ goeie resep het. Aan die ander kant kan die volgende grondliggende probleme ten opsigte van baie van die Onafhanklike Afrika Kerke geïdentifiseer word. Sonder om op elke punt uit te brei, word hulle slegs genoem.

* Die gebrek aan teologiese opleiding en ' $\mathrm{n}$ hermeneutiese aanvoeling.

* Hierdie gebrekkige kennis lei meermale tot dwaling en ' $n$ wanbegrip van basiese Skrifwaarhede. Dit maak die deur vir (negatiewe) sinkretisme wyd oop.

* Waar die Bybel wel gebruik word, word dit meestal op ' $\mathrm{n}$ biblisisties, letterlike en wettiese wyse gedoen.

* Die proses van inkulturasie word verder as sy Bybelse grense gevoer, met die gevolg dat dit tot allerlei sinkretistiese verskynsels en trekke lei.

* Onafhanklik is hierdie Kerke wel, maar die afwesigheid van betekenisvolle kontak met die algemene (katolieke) kerk lei daartoe dat die proses van kritiese inkulturasie ontbreek.

Die aangewese benadering wat ons insiens gevolg behoort te word, is dié van konstruktiewe betrokkenheid en gesprekvoering. Daar moet eerstens erken en bely word dat die historiese kerke in die verlede té verwerpend en negatief teenoor hierdie kerke opgetree het. Karikature is van hulle gemaak en dit het die afstand net verder vergroot. Daar sal ook erken moet word dat hierdie Kerke in baie opsigte as voorbeeld vir die historiese jong-kerke kan dien in hulle groei, entoesiasme, en - dit is hier die hoofsaak - hulle vermoë om die mense van Afrika te laat tuisvoel. In die kontak en gesprekvoering sal natuurlik wegbeweeg moet word van die tipies Westerse analitiese en rasionele denkpatrone. Dit is juis op hierdie punt dat die inkulturasie dikwels misgeloop het.

Wat veral belangrik is, is dat die kontak en gesprek hoofsaaklik gevoer sal moet word deur daardie Christelike Afrika-kerke wat uit die sending of uit die historiese kerke ontstaan het. Vanuit hierdie kerke, met " $n$ inherente begrip vir die lewens- en wêreldbeskouing van die Afrikaan, kan ' $n$ kragtige getuienis na die Onafhanklike Swart Kerke uitgedra word. Hulle kan daaraan herinner word dat hulle deel van die 
universele kerk van Christus is, en dat daar bepaalde universele, Christelike leerstellings is wat hulle moet onderskryf as hulle waarlik kerk van Christus wil wees.

In plaas daarvan om die Onafhanklike Swart Kerke as "n brug vanaf die Christendom terug na die heidendom te sien, moet hulle eerder - oor die algemeen - as " $n$ brug tot die evangelisering van tradisionele Afrika gesien word ${ }^{14}$.

\section{0 'N TWEE-DIMENSIONELE OEFENING}

Ten slotte wil ons, in die lig van wat hierbo behandel is, graag ' $n$ moontlike tipologie voorstel wat gebruik kan word om nie alleen die Onafhanklike Afrika Kerke te beskryf nie ${ }^{15}$, maar eintlik die hele spektrum van christelike Kerke in Suid-Afrika. Hierdie sou terselfdertyd gebruik kon word om die spektrum van negatiewe tot positiewe sinkretisme / inkulturasie te illustreer. In die Suid-Afrikaanse konteks vind beide verwestering en afrikanisering van die Christelike geloof plaas. In die proses kom die hele spektrum vanaf negatiewe tot positiewe sinkretisme na vore ${ }^{16}$.

14 J J Kritzinger (2001:1119-1133) het in ' $n$ artikel die brug-funksie van die Onafhanklike Swart Kerke ondersoek.

15 Alhoewel daar al heelwat tiperings ontwerp is, is dit veral die een van Sundkler (1948 en 1960) wat as basis gebruik word: Ethiopies, Sionisties ("Geestipe"... volgens Crafford 1988) en Messiaans.

16 Die feit is dat die Suid-Afrikaanse bewegings ' $n$ wye verskeidenheid vertoon. Dit is nie alleen die geval binne die sg Afrika Onafhanklike Kerke as groep met (letterlik) duisende Kerkies nie, maar kan ook opgemerk word intern binne die groter Kerke, soos die Zion Christian Church (ZCC), die iBandla lamaNazaretha, en ander tradisionele kerkformasies. Die probleem met die formulering van ' $n$ gepaste tipologie is juis hierdie verwarrende verskeidenheid, asook die feit dat dit moeilik is om in baie gevalle presies aan te dui waar " $n$ bepaalde Kerk(ie) staan, of waarin hulle inderdaad glo. Baie het nie 'n Kerkorde en/of Belydenisskrifte nie. Daar is bitter min sistematies oor meeste van hierdie kerke of bewegings beskikbaar om werklik te kan bepaal wat hulle Skrifbeskouing en Christologie is. Trouens, hulle ortodoksie word meestal gemeet aan die mate waarin dit met die beskouings van die historiese kerke ooreenstem en by ekumeniese liggame inpas. Dit is natuurlik - per definisie - nie billik nie. Om ' $n$ algemene standaard wat vir almal geld, neer te lê, is feitlik ' $n$ saak van onmoontlikheid. Hiervoor sal ' $n$ grondige studie van elke kerk of beweging gedoen moet word. In sekere kerke of bewegings word byvoorbeeld ' $n$ hoë graad van dissipline en beheer aangetref. Ander is weer feitlik onbeduidend klein en funksioneer as ' $n$ klein kringetjie om "n charismatiese leier. Baie ander groepe het 
Ter aanvulling van die gewone horisontale indeling van die Kerke en bewegings in drie of vier tipes wil ons ook waag om ' $n$ vertikale dimensie hiermee te kombineer, om sodoende 'n twee-dimensionele tipologie daar te stel.

Ons dink aan ' $n$ indeling volgens twee kontinuums:

* Op die een (horisontale) as kan bewegings geplaas word op ' $n$ kontinuum volgens hulle houding ten opsigte van die inheemse (Afrika- of Westerse) kultuur: 'n volledige omhelsing daarvan aan die linkerkant (A, dis nou Abelardus se opsie), en ' $n$ volledige verwerping daarvan aan die regterkant (B: Tertullianus se standpunt). Daarmee word natuurlik nie gesê dat een of ander kant van die spektrum reg is en die ander verkeerd nie. Trouens, uit die voorgaande sal afgelei kan word dat negatiewe sinkretisme by beide hierdie ekstreme posisies voorkom: 'n volledige omhelsing van die kultuur dra uiteraard christelik-vreemde elemente in die christelike geloofslewe in, terwyl 'n volledige verwerping van die kultuur die ou denkbeelde en gewoontes net ondergronds dryf, vanwaar dit die christelike geloof ondergrawe. Dit sou waarskynlik nie te ver verkeerd wees om die ideaal iewers in die middel te plaas nie. Elke beweging sal inderdaad êrens tussen die twee uiterstes van A en B geplaas word, maar dit sal tog moontlik wees om ' $\mathrm{n}$ tendens te identifiseer.

* Op die vertikale vlak word "n teologiese spektrum voorgestel: vanaf "vrysinnige (liberaal-globaliserende) teologie" bo (by C) tot " $n$ fundamentalistiese teologie onder (by D). Dieselfde opmerking sal ook hier gemaak kan word: beide ekstreme moet verkieslik vermy word, sonder om te sê dat die ideaal reg in die middel sou lê. Uiteraard sal dit ook hier geld dat die meerderheid Kerke na een of ander kant van die sentrum sal neig.

weer groot getalle en openbaar 'n wye verskeidenheid geloofsopvattings en gebruike binne dieselfde beweging. Terwyl dit waarskynlik nie korrek is om elkeen van hierdie "kerke" as "christelik" te tipeer nie, is dit aan die ander kant net so verkeerd om hulle te ignoreer of bloot as nie-christelik af te maak. 


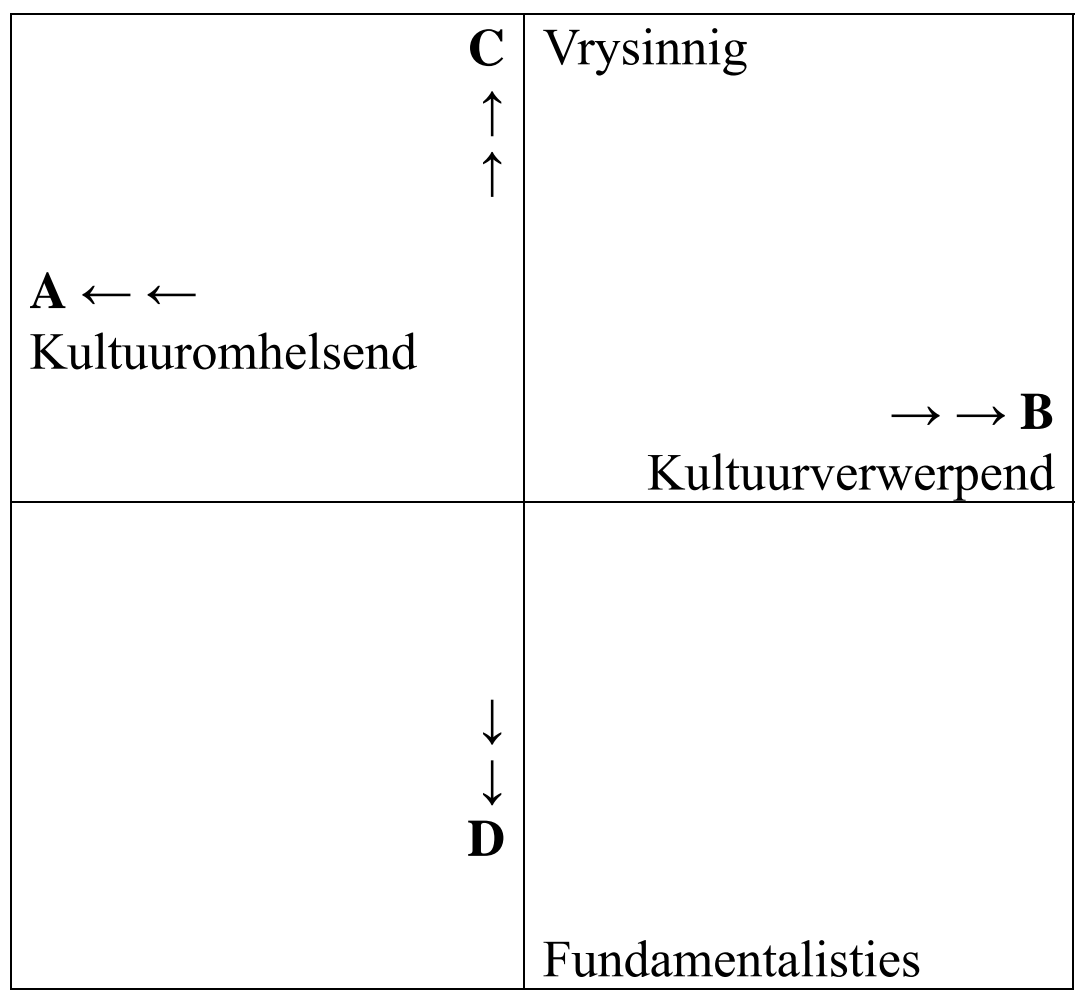

Die indeling wat aan die hand hiervan gemaak kan word, is soos volg:

- Geïnkultureerde kerke of bewegings (AD sektor). In hierdie kerke of bewegings het inkulturasie redelik gebalanseerd verloop. Die teologie wil Bybels wees, tog word die kultuur waardeer en benut vir die uitbreiding van die koninkryk van God. Die positiewe kant van die "volkskerk" gedagte van die NHKA toon iets hiervan. Die sogenaamde "Ethiopiese Kerke" kan ook hier geplaas word: hulle behou die oorgelewerde teologie, maar plaas hulleself bewustelik in ' $n$ bepaalde bevolkingsgroep. Die sinkretisme wat hier voorkom, kan as aanvaarbaar beskou word as die konserwatiewe teologie " $n$ sterk genoeg korreksie bring.

- $\quad$ Biblisisties-konserwatiewe kerke of bewegings (BD sektor). Hierdie kerke of bewegings handhaaf ' $n$ sterk fundamentalistiese teologie, en neig (daarom) om verwerpend teenoor kultuur te staan. Baie van die "evangelical-pentecostal" bewegings of kerke val in hierdie sektor. So val ook die sendingbenaderings waar die evangelie in ' $n$ Westerse gewaad en Westerse kultuurvorme oorgedra is, en die inheemse kultuur geïgnoreer is, in hierdie sektor. Die sinkretisme wat hier voorkom, is bedek en negatief, want dit word nie herken nie. 'n Dualisme vat pos. 
- Liberaal-globaliserende kerke of bewegings (BC sektor). Hierdie is kerke of bewegings wat kultuur-verwerpend is, en terselfdertyd ' $n$ liberale teologiese grondhouding handhaaf. ' $n$ Voorbeeld hiervan is die moderne (of postmoderne) filantropiese inisiatiewe wat (bewustelik of onbewustelik) uitverkoop is aan die een (Westerse) wêreldkultuur en een wêreldgodsdiens. Die sinkretisme wat hier voorkom is dié tussen ' $\mathrm{n}$ bepaalde postmoderne kultuur en die gepaardgaande teologiese visie. Nie veel Afrika-kerke sal hier geplaas kan word nie. Ons beoordeel hierdie sinkretisme as negatief.

- Kwasie-Christelike kerke of bewegings (AC sektor). In hierdie kerke of bewegings word inkulturasie tot die uiterste konsekwensie gevoer, maar basiese en essensiële Skrifwaarhede bly in die slag omdat daar geen behoorlike teologiese onderbou is nie. Hier vind ons sommige van die Onafhanklike Swart Kerke (byvoorbeeld die amaNazaretha), waar sterker op die ou tradisionele vorme gebou word as op die Skrif. Hierdie is negatiewe sinkretisme.

Op grond van hierdie tiperings kan nou ook 'n nadere indeling van die Onafhanklike Afrika Kerke op die sinkretistiese spektrum gemaak word. In hierdie verband volg ons grootliks Gilliland (1986:266) se bruikbare benadering en model, wat grootliks met ons skema ooreenstem $^{17}$. Natuurlik is dit nie moontlik om groepe in waterdigte kompartemente in te deel nie, maar tog kan die volgende indeling aangebied word:

\section{(a) Hoofsaaklik evangeliese ${ }^{18}$ groepe}

In hulle struktuur, rituele en belydenis openbaar hierdie groep baie trekke van die historiese kerke en kerke wat uit sendingwerk ontstaan het. Kerke van die Ethiopiese tipe kan ook hieronder geklassifiseer word. Uiteraard sal weinig negatiewe sinkretisme hier voorkom. Op die sinkretistiese spektrum word hulle links (positief) geplaas.

17 Hier moet in gedagte gehou word dat Gilliland homself bewustelik in die evangeliese stroom plaas, en dat sy hoof-onderskeiding dus is tussen "evangelies" en "tradisioneel" (waarmee hy ongeveer teologies-sinkretisties bedoel). Die "evangeliese" kant is dus die naaste aan reg!

18 "Evangelies" word hier as baie dieselfde as "Bybels-Gereformeerd" gebruik. 


\section{(b) Sekondêr evangeliese groepe}

Hierdie groepe maak daarop aanspraak dat die Bybel in hul godsdiens sentraal staan, maar van enige teologiese opleiding is daar feitlik geen sprake nie. Groot klem word geplaas op direkte openbaringe, drome en visioene, en hul leiers is meer charismaties-profeties. Onder hierdie groep kan die ZCC geplaas word. Hierdie is christelike Kerke, maar die inkulturasie loop die gevaar om negatiewe sinkretisme te word.

\section{(c) Openbarend tradisionele groepe}

Hierdie kerke word gekenmerk deur hulle radikale independentisme en sektarisme. Hier is die direkte openbarings wat die kerkleier ontvang van groter waarde as die Skrifopenbaring, alhoewel die Bybel ook gebruik word. Drome, visioene en profetisme kom hier algemeen voor. Tradisionele kultuurgebruike kom sterk na vore, en groot klem word op die (tradisionele en Ou Testamentiese) rituele geplaas. Wat die Bybel betref, is dit veral die Ou Testament wat letterlik beklemtoon word. Oorwegend negatiewe sinkretisme kom hier voor.

\section{(d) Eklekties tradisionele groepe}

By hierdie groepe kom negatiewe sinkretisme algemeen voor. Hulle openbaar sóveel tradisionele kenmerke dat hulle byna nie as "Christelik" beskou kan word nie. Hulle word as "tradisioneel" bestempel omdat die rituele en gebruike van die tradisionele godsdiens hier oorheersend aanwesig is. Die groepe wat Sundkler as "nativisties" bestempel het, word hieronder geklassifiseer. Alhoewel die amaNazaretha baie trekke van die vorige groep openbaar, is dit verkieslik om hulle onder hierdie groep te plaas. Op die spektrum is hulle regs (negatief).

\section{SLOT}

Dit is herhaaldelik beklemtoon dat die tradisionele kultuur en godsdiens nie sonder meer en ongekwalifiseerd van die tafel gevee moet word ten gunste van die Westerse-gekleurde sending se teologie nie. Aan die ander kant kan alles van die ou kultuur egter nie maar net so aanvaar word nie. Dit is dalk gepas om weer herinner te word aan Crafford (1996:22vv) se opmerkings oor die veranderings wat in die tradisionele lewens- en wêreldbeskouing nodig is om te kan inpas by die christelike visie:

- Verandering vanaf ' $n$ geslote, sakrale kosmos na 'n oop gedesakraliseerde kosmos; 
- Verandering vanaf ' $\mathrm{n}$ mitologiese benadering na ' $\mathrm{n}$ historiese benadering;

- Verandering vanaf ' $n$ geslote sakrale stamgemeenskap na 'n oop pluralistiese gemeenskap;

- Verandering vanaf rituele pligte na morele verantwoordelikhede.

"n Mate van "sinkretisme" is in Afrika - soos wat dit die geval was met die oorgang van die evangelie na enige nuwe kulturele sisteem noodsaaklik. In hierdie proses moet primêr vertrou word op die werk van die Heilige Gees in ' $n$ inheemse geloofsgemeenskap. Kritiek van buite ten opsigte van hierdie proses behoort alleen met groot nederigheid en met verwondering geskied.

\section{Literatuurverwysings}

Bavinck, J H 1949. The Impact of Christianity on the Non-Christian World. Grand Rapids: Eerdmans.

Beyers, J 2003. Analities-deskriptiewe oorsig van die gebruik van die term sinkretisme: "Die definisie van die probleem en die probleem met die definisie" HTS 59(1), 1-30.

Bosch, D J 1974. Het Evangelie in Afrikaans Gewaad. Kampen: Kok.

Bosch, David J 1991. Transforming Mission. Paradigm Shifts in Theology of Mission. Maryknoll: Orbis Books.

Crafford, D D 1988. Uitdagings vir die Kerk in Afrika. Pretoria: Universiteit van Pretoria Teologiese Studies 8.

-, 1996. 'Tradisionele Godsdienste in Afrika', in: Meiring, P G J (red). SuidAfrika. Land van Vele Godsdienste, 1-28, Pretoria: Kagiso Uitgewers.

Gilliland, D S 1986. How "Christian" are African Independent Churches? Missiology: An International Review 14(3), 259-271.

Glasser, A F, Hiebert, P G, Wagner, C P and Winter, R D 1976. Crucial Issues in World Evangelization. Pasadena: William Carey Library.

Hiebert, P G 1976. "Culture and Cross-cultural differences", in Glasser, Arthur F e a, 45-60.

Hiebert, P G 1999. Anthropological Insights for Missionaries. $14^{\text {th }}$ print. Grand Rapids: Baker Book House.

Karecki, M M 1993. Inculturation: an imperative of mission. Missionalia 21(2), 152-158.

Kraemer, H 1938. The Christian Message in a Non-Christian World. London: Edinburgh House Press.

Kritzinger, J J 2001. Welkom by die brug! Opmerkings oor die brug-funksie van die Afrika onafhanklike kerke. HTS 57(2+4), 1119-1133.

Neill, S 1964. A History of Christian Missions. London: Penguin Books. 
Niemand, S J J 2000. Sinkretisme as Teologiese Uitdaging, met besondere verwysing na die Ibandla Lamanazaretha. Ongepubliseerde $\mathrm{PhD}$ proefskrif, UP.

Schineller, P 1992. Inculturation and Syncretism: what is the real issue? International Bulletin of Missionary Research 16(2), 50-53.

Sundkler, B G M 1961. Bantu Prophets in South Africa. London: Oxford University Press.

Van den Berg, M R 1966. Syncretisme als Uitdaging. Amsterdam: Buijten \& Schipperheijn.

Van der Merwe, G 1990. Syncretism in South Africa. NGTT 31(3), 417-423.

Van Rooy, J A 1964. Sinkretisme onder die Separatistiese Sektes in Vendaland. Ongepubliseerde MTh skripsie. PU vir CHO.

Verstraelen, F J 1981. Afrikaans Christendom tusschen verleden en toekomst. Wereld en Zending 10(1), 4-19.

Whiteman, D L 1997. Contextualization: the Theory, the Gap, the Challenge. International Bulletin of Missionary Research 21(1), 2-7. 